\title{
Microbial fuel and chemical production using sweet potatoes
}

\author{
M. Ntoampe ${ }^{1,2}$, T. Matambo ${ }^{2}$, D. Glasser ${ }^{2}$ \& D. Hildebrandt ${ }^{1,2}$ \\ ${ }^{1}$ School of Chemical and Metallurgical Engineering, \\ University of the Witwatersrand, South Africa \\ ${ }^{2}$ Centre of Material and Process Synthesis, South Africa
}

\begin{abstract}
Bioconversion of renewable resources into useful chemicals and fuels is of great interest in scientific research. This is mainly because of the gradual depletion of fossil fuels and the increasing price of oil. The objective of this research is to produce biologically based chemicals and fuels from sweet potatoes. The sweet potato is a crop of choice because it has a high starch content and is rich in $\beta$-amylase, which converts long chained starch into readily used maltose units, making it a good energy and carbon source for bacteria. A Fluidized Bed Bio-Reactor (FBBR) was used as a fermentation tank, in which bacteria were metabolizing and converting sweet potatoes into end products, such as fuel ethanol and hydrogen gas. On the other hand, plate counts were used to estimate the number of viable cells in a reactor. Any increase in the number of cells would be an indication of increasing cell density, which would imply increased microbial activity and hence elevated gas and chemical production by the microbes used in the reactor. Gas Chromatography (GC) was used to analyze the end products, i.e. in separating components of the liquid mixture into pure components. This was the key to establishing which gases and liquids were produced during FBBR operation. GC analysis revealed that 5\% ethanol, 2.5\% acetic acid, $2 \%$ propionic acid and 3\% butyric acid were produced. Hydrogen and methane were also produced in amounts that were not measured.
\end{abstract}

Keywords: sweet potato, fermentation, fluidized bed bio-reactor, ethanol, acetic acid, propionic acid, butyric acid, methane, hydrogen. 


\section{Introduction}

Bioconversion of renewable resources into useful chemicals is of great interest in scientific research $[1,2]$. This can be attributed to their abundance and the fact that they do not increase carbon dioxide $\left(\mathrm{CO}_{2}\right)$ levels in the atmosphere $[1,3]$. Renewable materials include biomass such as industrial residues (e.g. byproducts of paper manufacturing), agricultural residues (e.g. husks of corn plants) and energy crops (e.g. sugarcane) [2-4].

Conversion of these residues and crops results in production of key chemicals such as ethanol, acetone, butanol, isopropanol, carboxylic acids, butanediols as well as gases such as $\mathrm{CO}_{2}$, hydrogen and methane $[1,2]$. Some of these products may be used as supplements or alternatives to fossil fuels which are currently running out [3].

In cases where crops are used as biomass, it is very important to use a crop that is suitable for production of useful products [2]. The crop of choice should be easy to grow and harvest [5]. Sweet potatoes are of great potential for use in production of useful industrial chemicals mostly because of their high starch content $[4,6]$.

Sweet potatoes contain moisture, ash and most importantly the basic chemical building blocks -carbohydrates [6, 7]. As illustrated by Hosein and Mellowes [7] the carbohydrate content comprises of about $20 \%$ starch and $4 \%$ sugar. In addition to this, sweet potatoes' carbohydrate has been reported to contain pectin substances, lignin, cellulose and hemicellulose [6]. All these components can be fermented into useful industrial chemicals [2].

Reportedly, not all bacteria can readily use starch as their energy and carbon source [8]. This means that some starches need to be broken down to simple fermentable sugars so as to be utilized by many bacteria [8]. On the other hand, sweet potatoes are rich in $\beta$-amylase which converts long chained starch into readily used maltose units making it a good energy and carbon source for many bacteria [8].

In addition to sweet potatoes having higher starch content compared to other carbohydrate crops such as corn, they have high yield capacity making them a potential biomass resource for producing useful industrial chemicals [4, 5]. This was illustrated by Mays et al. [5], who investigated alcohol production from sweet potato, sweet sorghum, sugar beet, fodder beet and potato. Results obtained revealed that sweet potatoes yielded the highest alcohol per hectare when compared with other crops.

Sweet potatoes, like other starch and sugar crops may be used to produce liquid or solid fuels such as ethanol through fermentation [2, 8]. The starch found in sweet potatoes can also be used in the production of acetone, butanol, lactic acid and brewing materials which can be used as key substrates in the production of other chemicals [1].

To date, very little work has been carried out on sweet potatoes as a source of chemical production. The few studies that have been carried out only focus on the production of fuels such as, hydrogen and ethanol but not on other industrial chemicals $[6,7,9]$. In addition to this, most studies that use sweet potatoes only 
use purified starch or sugars [4, 9]. No work has been done on the use of a fresh raw sweet potato on production of a range of chemicals, which is the focus of this study.

\section{Materials and methods}

\subsection{Bio-reactor description}

The FBBR used in this study was constructed from clear perspex (acrylic). The column was $100 \mathrm{~cm}$ high and could hold a volume of $6 \mathrm{~L}$. Granular activated carbon (GAC) (SIGMA, RSA) was fluidized in an internal diameter of $10 \mathrm{~cm}$. The bio-reactor had an outer water jacket for temperature regulation at $45^{\circ} \mathrm{C}$ that was connected to a water bath. The medium was fed into the reactor from the bottom while produced chemicals were collected via the overflow port. Gases were collected from the top of the reactor (Figure 1)

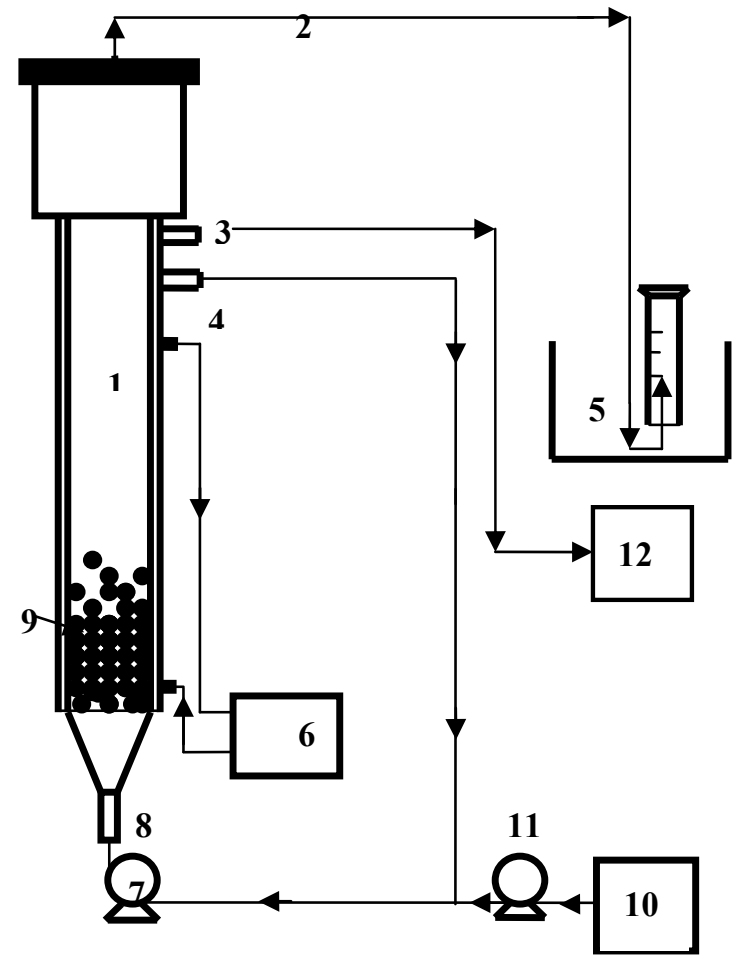

Figure 1: $\quad$ Schematic illustration of FBBR used. 1- Column, 2- Gas sampling site, 3- Overflow site, 4- FBBR outlet, 5- Gas collection, 6waterbath $\left(30^{\circ} \mathrm{C}\right), 7$ - recycle pump, 8- FBBR inlet, 9- GAC, 10Reservoir, 11- peristaltic pump, 12- Product collection. 


\subsection{Sterilization of FBBR}

Prior to inoculation, the bio-reactor was rinsed with $20 \%$ sodium hypo chloritecontaining sanitizer for 1 hour followed by neutralizing buffer (Difco) for 1 hour and then flushed with sterile distilled water as previously described in [10].

\subsection{Bacterial strains}

Bacteria were isolated from $1 \mathrm{~g}$ of fresh sweet potato incubated for four days at $30^{\circ} \mathrm{C}$. Bacteria were scrapped (loop full) from the incubated sweet potato and inoculated into $50 \mathrm{ml}$ sterile distilled water and shaken at $100 \mathrm{rpm}$ overnight at $30^{\circ} \mathrm{C}$. The resultant culture was serially diluted $(1: 1000)$ and plated on Nutrient agar (Biolab, Wadeville, Gauteng, RSA). Plates were incubated overnight at $30^{\circ} \mathrm{C}$. Single individual colonies were selected based on differences in colony colour and mixed together to form a consortium. The isolated consortium was stored on Tryptone Soya Agar (TSA) (Oxoid) plates at $4^{\circ} \mathrm{C}$.

\subsection{Growth curve of the consortium}

Growth curve of the isolated consortium was generated by standardizing overnight culture grown in $50 \mathrm{ml}$ nutrient broth (NB) (Biolab, Wadeville, Gauteng, RSA). The overnight culture was diluted 1/100 from which $0.5 \mathrm{ml}$ sample was then transferred into $50 \mathrm{ml}$ of $\mathrm{NB}$ and incubated at $30^{\circ} \mathrm{C}$ with shaking at $100 \mathrm{rpm}$ overnight. Duplicate optical density (OD) readings at $600 \mathrm{~nm}$ were measured every 2 hours over a 16-hour period interval using cuvettes of a light path of $1 \mathrm{~cm}$. The experiment was performed in duplicates. The obtained $\mathrm{OD}_{600 \mathrm{~nm}}$ readings were averaged and used to construct a growth curve by plotting the readings against time. The growth curve was used to determine the species optimum growth as this directly relates to the optimum biofilm growth.

\subsection{Inoculum preparation for Bio-reactor}

The consortium of mixed cultures was grown in $50 \mathrm{ml} \mathrm{NB}$ for 4 hours at $30^{\circ} \mathrm{C}$ (mid-log growth phase for the consortium). This was used to inoculate the bioreactor.

\subsection{Biofilm establishment}

Granular activated carbon (GAC) (200g) was used as a biofilm carrier or attachment medium in FBBR due to its slight electro-positive charge making it more attractive to chemicals and impurities. Different functional groups on the GAC also increase microbial attachment while its rough surface provides excellent shelter and protection for bacterial attachment.

\subsection{FBBR set-up and operation}

FBBR was setup and sterilized as previously described. The mixed culture suspension $(5 \mathrm{ml})$ was used to inoculate the bio-reactor containing nutrient media 
(One-tenth of the total volume of the bio-reactor). The culture was allowed to grow and recycle through the reactor for 21 days to allow for biofilm establishment. Once biofilm was established, NB was replaced with modified GP growth medium (polypeptone, $2 \% ; \mathrm{KH}_{2} \mathrm{PO}_{4} 0.2 \%$; $\mathrm{MgSO}_{4} .7 \mathrm{H}_{2} \mathrm{O}, 0.05 \%$; yeast extract, $0.05 \%$; $\mathrm{pH} 6.5$ ) containing $250 \mathrm{~g}$ of fresh sterilized sweet potatoes cut in cubes (Yokoi et al. [6])

The bio-reactor operation was performed in two phases; initial batch operation followed by continuous operation. Batch operation was performed mainly to establish biofilm attachment on GAC particles. Once established the system was switched to continuous mode.

Experimental controls were included so as to determine the exact products of sweet potato fermentation. In Control 1 (C1), FBBR was operated as previously described but without the inoculum. In Control 2 (C2), the FBBR was also operated as previously described but the media contained no sweet potatoes. Control 3 (C3) FBBR, involved the use of distilled water only (no sweet potatoes and bacterial consortium).

\subsection{Analyses}

The liquid products (alcohols and volatile fatty acids) were analyzed using an Agilent 6820 gas chromatograph (Agilent Technologies, Supelco, 24107, USA) equipped with a thermal conductivity detector (TCD). The operational temperatures of the oven and the detector were $185^{\circ} \mathrm{C}$ and $155^{\circ} \mathrm{C}$, respectively. The samples were separated on a fused silica capillary column $(30 \mathrm{~m} \times 0.25 \mathrm{~mm}$, $0.25 \mu \mathrm{m}$ film thickness) using Helium as the carrier gas at a flow rate of $20 \mathrm{ml} / 0.01 \mathrm{~min}$. Product liquid samples $(1 \mathrm{ml})$ were collected from the bioreactor and $0.2 \mu \mathrm{l}$ of the sample was injected manually into the GC. Gas samples were collected from the top of the reactor and analyzed using a Dani GC (Dani 1000) with pora pack $Q$ column equipped with a TCD detector. The oven temperature was at $200^{\circ} \mathrm{C}$. Argon was used as the carrier gas. Injection port temperature was kept at ambient while the detector temperature was $120^{\circ} \mathrm{C}$. Peak identification of products was based on retention times of reference standards.

\section{Results and discussion}

The growth curve shows all the four distinct phases lag, log, stationary and decline (death phase). The isolated cultures reached the mid-log phase after four hours of incubation and showed maximum growth on the tenth hour, after which the stationary phase was reached. It maintained the stationary phase stage for about six hours (Figure 2).

The mixed bacterial population used in this study exhibited normal batch bacterial growth curve as the curve had all the four identifiable phases. The lag and the death or decline phase were quite brief with each lasting only for about 2 hours. This could result from the fact that spectrophotometric determination of bacterial densities is sensitive enough to log and stationary phase but not to lag and death phase which are normally very slow [11]. 


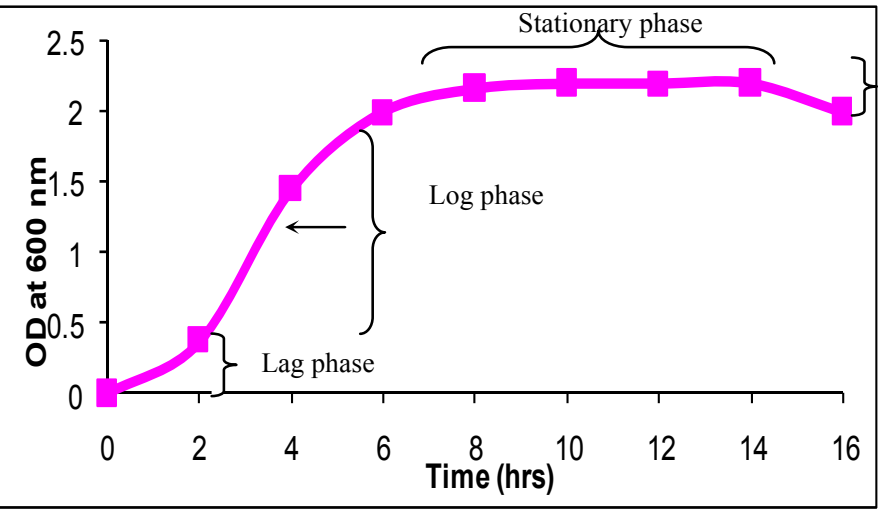

Death phase

Figure 2: Optical Density (OD) growth curve of bacterial consortium isolated from sweet potatoes. The consortium was grown in NB; OD at $600 \mathrm{~nm}$ determined every 2 hours over a 16- hour period. The arrow indicates the stage of growth at which the isolates were inoculated within the bio-reactor.

$5 \%$ ethanol, $2.5 \%$ acetic acid, $2 \%$ propionic acid and $3 \%$ butyric acid were produced in the experiment bio-reactor containing sweet potatoes and bacterial consortium (Figure 3a). Fermentation reactions occurred in solutions made up in water hence the large water peak that appeared at time 4 minutes (Figure 3 ). In both controls $\mathrm{C} 1$ (containing no bacterial inoculum) and $\mathrm{C} 2$ (Containing no sweet potatoes), acetic acid was produced (Figures $3 \mathrm{~b}$ and $3 \mathrm{c}$ ). However, in control $\mathrm{C} 1$, propionic acid was also produced (Figure $3 \mathrm{~b}$ ). In control $\mathrm{C} 3$, where the bio-reactor was operated with distilled water, only water peak was detected as would be expected (Figure 3d).

Acetic acid is a by-product of starch and sugar fermentation, this could explain its presence in the test and C2 experiments (Figures 3a and 3c) [12]. Control $\mathrm{C} 1$, with no bacteria added had peaks for acetic acid and butyric acid. These products may arise from the fermentation of sweet potatoes as a result of the bacteria present on the sweet potatoes (Bacteria used in the test experiments were originally isolated from sweet potatoes).

Hydrogen, carbon dioxide, nitrogen and methane were detected in the test experimental bio-reactor containing sweet potatoes (Source of carbon) and bacterial consortium (fermenting microorganisms) (Figure 4a). In Control C1, in which the bio-reactor was run without sweet potatoes, carbon dioxide, nitrogen and methane were detected (Figure 4b). While in Control C2 where no bacterial consortium was added, carbon dioxide and nitrogen were detected. Control C3, in which the FBBR was operated using distilled water, only nitrogen gas was detected. Nitrogen gas detected in all bio-reactors may be the result of atmospheric nitrogen introduced when setting up experiments (Internal gases were not flashed out at the start of the experiments). 

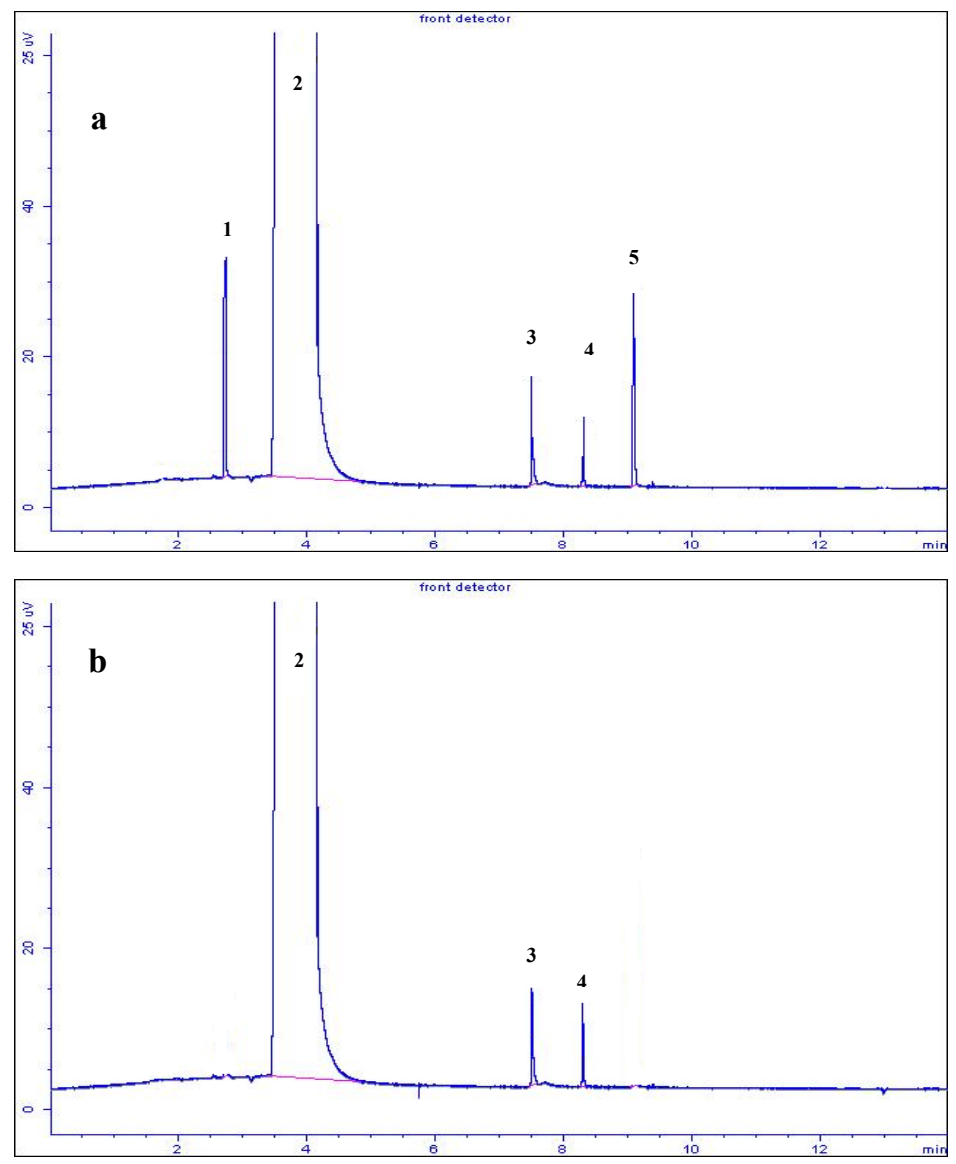

Figure 3: GC spectra of organic compounds obtained from sweet potato fermentation. a) Experiment bio-reactor where both sweet potatoes and mixed cultures were used, b) Control 1 (C1): bio-reactor operating without inoculum, c) Control 2 (C2): bio-reactor operating without sweet potatoes, and d) Control 3 (C3): bioreactor operating with distilled water only. Peaks 1-5 were identified as ethanol, water, acetic acid, propionic acid and butyric acid respectively from a standard profile (data not shown). 

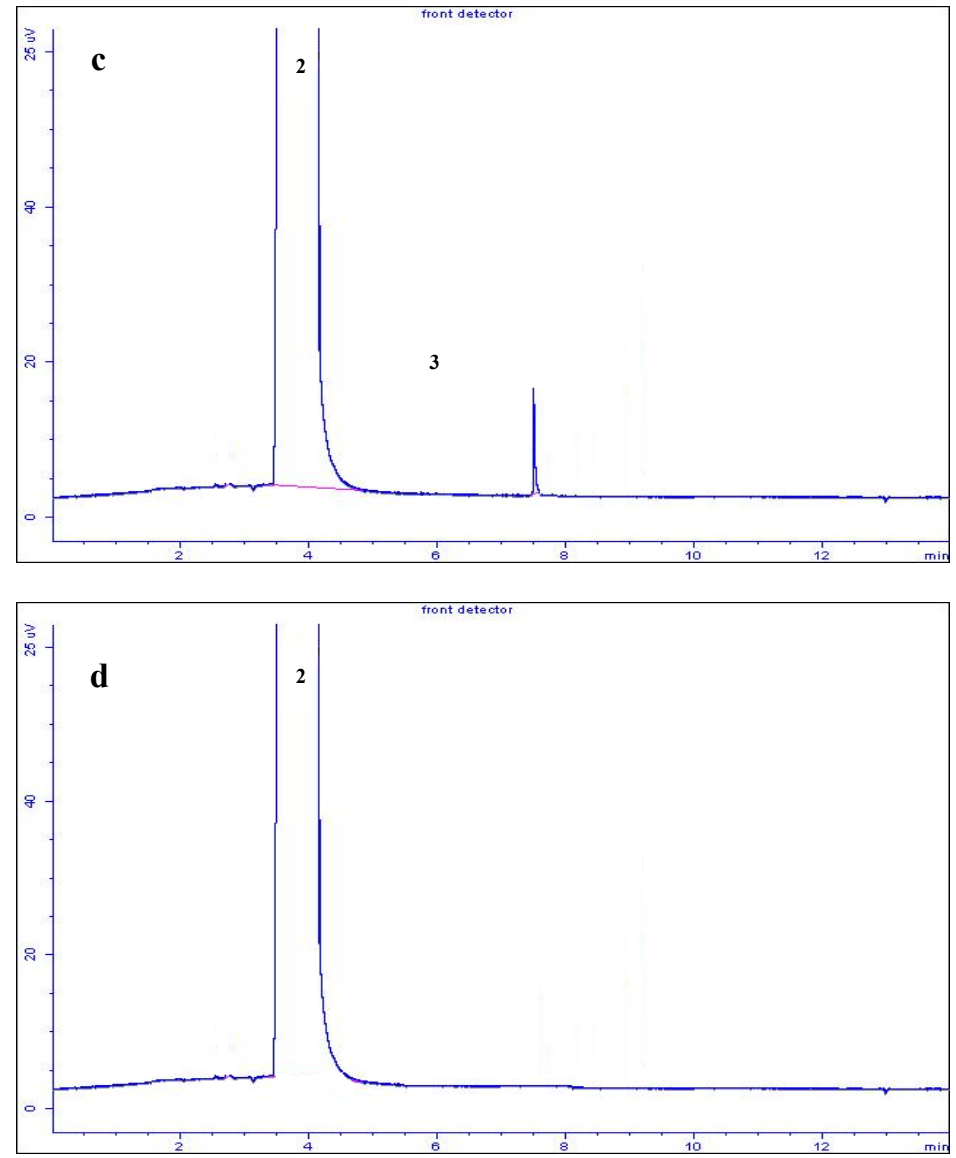

Figure 3: Continued. 

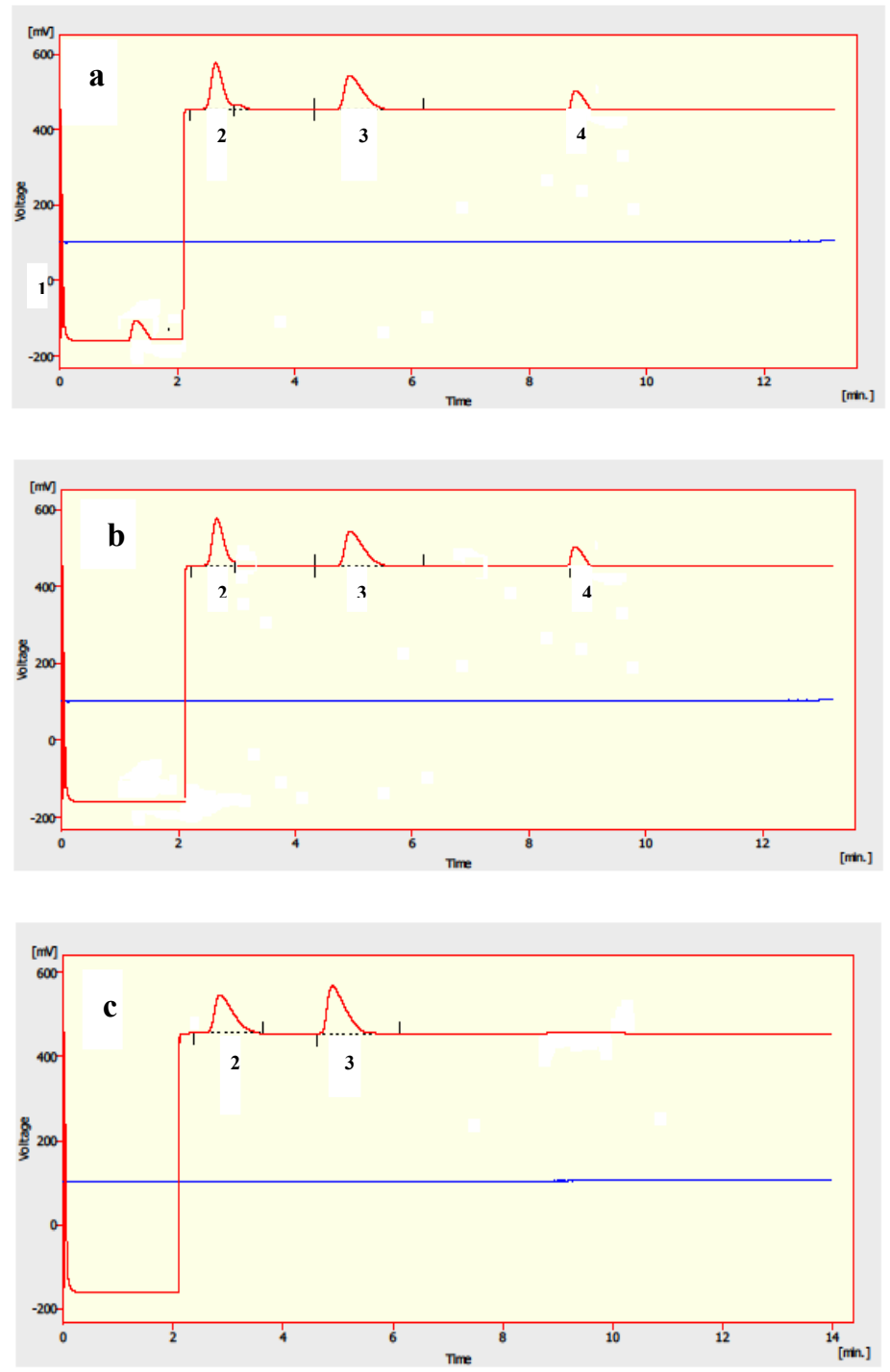

Figure 4: GC spectra of gases produced in bio-reactors. a) Test experimental bio-reactor containing sweet potatoes and bacterial consortium, b) Control C1: bio-reactor operating without bacterial consortium, c) Control C2: bio-reactor operating without sweet potatoes, and d) Control C3: bio-reactor operating with distilled water. Peaks 1-4 were gases identified as hydrogen, carbon dioxide, nitrogen and methane, respectively. 


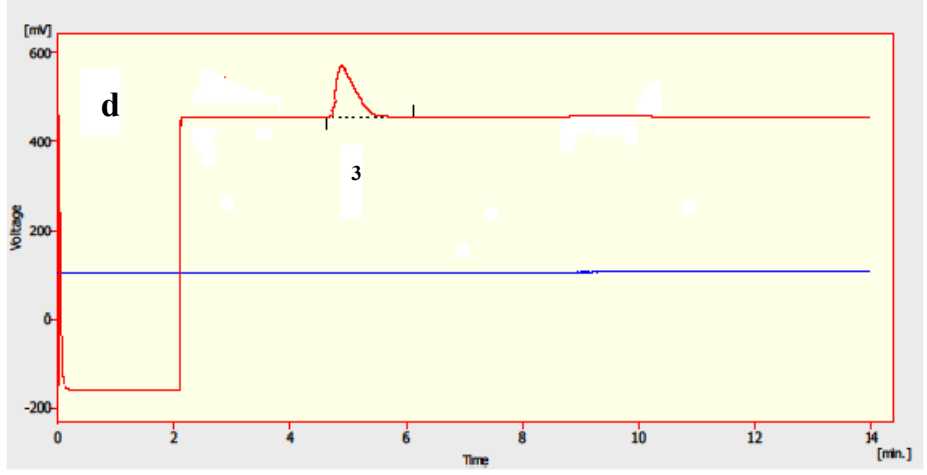

Figure 4: Continued.

\section{Conclusion}

Sweet potatoes have naturally occurring microorganisms associated with them. These microorganisms are involved in the breaking down of sweet potatoes into various compounds. Sweet potatoes contain sugar (4\%) and starch $(20 \%)$ that can be converted into liquid fuel such as ethanol and butanol as well as other useful industrial chemicals like acetic acid. In order to produce these chemicals, starch and sugar are fermented with the use of microorganisms. A Fluidized Bed Bio-Reactor was chosen for the fermentation of sweet potatoes because of its effectiveness in producing organic acids such as acetic acid, butyric acid and propionic acid.

Bacteria isolated from sweet potato were used in the fermentation process. GC analysis revealed that sweet potato fermentation produced liquid fuel ethanol as well as industrial chemicals: acetic acid, propionic acid and butyric acid. Gases that were produced were carbon dioxide, hydrogen and methane. Hydrogen may be used as a fuel while methane may be used to power electricity.

\section{References}

[1] Richter, K., \& Berhold, C., Biotechnological conversion of sugar and starchy crops into lactic acid. Journal of Agricultural Engineering Research, 71(2), pp.181-191, 1998.

[2] Antonopoulou, G., Gavala, H. N., Skiadas, I. N., Angelopoulos, K., \& Lyberatos, G., Biofuels generation from sweet sorghum: Fermentative hydrogen production and anaerobic digestion of the remaining biomass. Bioresource Technology, 99(1), pp. 110-119, 2008.

[3] Chew, T. L., \& Bhatia, S., Catalytic processes towards the production of biofuels in a palm oil and oil palm biomass-based biorefinery. Bioresource Technology, 99 (17), pp. 7911-7922, 2008.

[4] Dangler, J. M., Locascio, S. J., \& Halsey, L. H., Sweet Potato for Biomass. Biomass, 4(4), pp. 253-261, 1984. 
[5] Mays, D. A., Buchanan, W., Bradford, B. N., \& Giordano, P. M., Advances in new crops, In: J. Janick and J.E. Simon (eds.), Timber Press, Portland, pp. 260-263 (1990).

[6] Yokoi, H., Saitsu, A., Uchida, H., Hirose, J., Hayashi, S., \& Takasaki, Y., Microbial hydrogen production from sweet potato starch residue. Journal of Bioscience and Bioengineering, 91(1), pp. 58-63, 2001.

[7] Hosein, R., \& Mellowes, W. A., Malt Hydrolysis of Sweet-Potatoes and Eddoes for Ethanol Production. Biological Wastes, 29(4), pp. 263-270, 1989.

[8] Nigam, P., \& Singh, O., Enzyme and microbial systems involved in starch processing. Enzyme and Microbial Technology, 17(9), pp. 770-778, 1995.

[9] Yu, B., Zhang, F., Zheng Y. and Wang, P. U., Alcohol fermentation from the mash of dried sweet potato with its drags using immobilized yeast. Process Biochemistry, 31(1), pp. 1-6, 1996.

[10] Lindsay, D., Brozel, V. S., Mostert, J. F., \& von Holy A., Differential efficacy of a chlorine dioxide-containing sanitizer against single species and binary biofilms of a dairy-associated Bacillus cereus and a Pseudomonas fluorescens isolate. Journal of Applied Microbiology, 92(2), pp. 352-361, 2002.

[11] Casciato D. A., Stewart, P. R., \& Rosenblatt, J. E., Growth Curves of Anaerobic Bacteria in Solid Media. Applied Microbiology. 29(5), pp. 610614, 1975.

[12] Wronkowska, M., Soral- 'Smietana, M., Krupa, U., \& Biedrzycka, E., In vitro fermentation of new modified starch preparations - changes of microstructure and bacterial end-products. Enzyme and Microbial Technology, 40(1), pp. 93-99, 2006. 